\title{
Actividad antifúngica de melanina en cepas clínicas de Candida spp.
}

\author{
Marisol Fuentes, Romané Hernández, Diego Gordillo, José Amaro, Mary A. Falconer, \\ Claudio Alburquenque y Cecilia V. Tapia
}

\footnotetext{
Facultad de Medicina, Universidad de Chile, Santiago. Instituto de Ciencias Biomédicas, Programa de Microbiología y Micología, (MF, RH, DG, JA, MF, CT) Universidad Mayor, Santiago

Chile.

Escuela de Tecnología Médica (CA)

No existen conflictos de interés Fuentes de financiamiento: Fondos internos de Clínica Dávila, Proyecto Fondecyt de Iniciación 11110160.

Recibido: 26 de diciembre de 2012 Aceptado: 23 de noviembre de

\begin{abstract}
Antifungal activity of melanin in clinical isolates of Candida spp.
Background: Melanocytes are cells located in epidermis and mucous membranes that synthesize melanin and cytokines. It is known that melanin has antimicrobial activity and that melanocytes are melanized in presence of microbial molecules. Objective: To study the antifungal activity of melanin on Candida spp. Methodology: The minimum inhibitory concentration (MIC) to melanin was determined in 4 Candida ATCC strains (C. albicans SC5314, C. parapsilosis 22019, C. glabrata 2001, C. krusei 6258) and 56 clinical isolates of Candida spp. (33 C. albicans, 12 C. glabrata, 3 C. famata, 3 C. krusei, 3 C. parapsilosis, 2 C. tropicalis) using a broth microdilution method. In addition, the antifungal activity of melanocytes and mice melanoma cells was tested against $C$. albicans. Results: Melanin inhibited the tested isolates, including the susceptible dose-dependent and fluconazole-resistant strains; MIC range and MIC $_{50}$ were $0.09-50 \mu \mathrm{g} / \mathrm{mL}$ and $6.25 \mu \mathrm{g} / \mathrm{mL}$, respectively. Pigmented cells lysates inhibited C. albicans. Conclusions: Melanin is able to inhibit clinical isolates of Candida spp. Melanization could be an important protective mechanism of melanocytes.

Key words: Melanin, melanocyte, antifungal activity, Candida spp.

Palabras clave: Melanina, melanocito, actividad antifúngica, Candida spp.
\end{abstract}

\section{Introducción}

L os melanocitos son células dendríticas derivadas de la cresta neural que se localizan en el estrato basal de la epidermis interactuando con los queratinocitos en una razón de 1:30. Su principal función es la síntesis de un pigmento denominado melanina ${ }^{1,2}$.

Melanina es el nombre que recibe un amplio grupo de pigmentos con propiedades similares que se encuentra en la mayoría de los seres vivos; son polímeros de alto peso molecular muy estables, con polaridad negativa, hidrófobos e insolubles en agua ${ }^{3,4}$.

Los pigmentos de melanina se forman por polimerización oxidativa de compuestos fenólicos; en los melanocitos humanos se producen principalmente DOPA-melaninas, también denominadas eumelaninas, las cuales se caracterizan por ser pigmentos de color oscuro $^{5}$. La melanogénesis es un proceso que ocurre en organelos especializados llamados melanosomas, que se forman en el aparato de Golgi. Una vez sintetizada la melanina, ésta es transferida a los queratinocitos mediante exocitosis $1,2,6,7$.

Actualmente, no se conoce completamente el rol de la melanina en la piel y otros tejidos animales ${ }^{8}$. La principal función de la melanina en la piel humana parece ser la protección frente a los radicales libres formados por la radiación $\mathrm{UV}^{9,10}$. Sin embargo, existen estudios que rechazan esta hipótesis exponiendo que la melanina no resultaría efectiva por sí sola para evitar la formación de dímeros de pirimidina por radiación $\mathrm{UV}^{10,11}$.

Con respecto a otras funciones que se le atribuyen a melanina, estudios posteriores han demostrado una relación genética y bioquímica entre los procesos de inmunidad y melanización ${ }^{10}$. Dichos estudios han reportado que, tanto los melanocitos como la melanina, inhibirían la proliferación bacteriana y fúngica en la dermis y epidermis ${ }^{12}$.

Las especies del género Candida son levaduras comensales que forman parte de la microbiota gastrointestinal y genital, aunque bajo ciertas condiciones pueden transformarse en patógenos, produciendo una infección llamada candidiasis. El agente etiológico más prevalente es Candida albicans; sin embargo, se han aislado otras especies como C. glabrata, C. tropicalis, C. parapsilosis y C. krusei $i^{13}$.

Existe evidencia que sugiere que en población de piel oscura existiría una mayor resistencia a infecciones por Trychophyton mentagrophytes y C. albicans ${ }^{14}$. Dados los antecedentes expuestos, en el presente trabajo se desea evaluar si la melanina sintética, lisados de melanocitos y células de melanoma, presentan actividad antifúngica en cepas clínicas de Candida spp. 


\section{Materiales y Métodos}

\section{Cepas}

Se utilizaron cepas de Candida spp. ATCC (C. albicans SC5314, C. parapsilosis 22019, C. glabrata 2001 у C. krusei 6258) y 56 cepas provenientes de aislados clínicos de un cepario del Laboratorio de Clínica Dávila, las cuales fueron previamente identificadas a nivel de especie, mediante tubo germinativo, microcultivo y API $32 \mathrm{CAUX}^{\mathrm{TM}}$ (Biomerieux). Las cepas correspondieron a C. albicans (n: 33), C. glabrata (n: 12), C. famata (n: 3), C. krusei (n: 3), C. parapsilosis (n: 3) y C. tropicalis (n: 2). Se incluyeron en el estudio cepas susceptibles, susceptibles dosis dependiente (SDD) y resistentes a fluconazol. El uso de las cepas fue aprobado por el Comité de Ética de Clínica Dávila.

\section{Microdilución en caldo}

Se realizó un ensayo de microdilución en caldo, adaptando el estándar EUCAST-AFST para medir la concentración inhibitoria mínima (CIM), utilizando distintas concentraciones de melanina sintética (Sigma-Aldrich ${ }^{\circledR}$ ). Se prepararon placas de RPMI $16402 \mathrm{x}$ a pH 7,0 con concentraciones máximas de melanina de $50 \mu \mathrm{g} / \mathrm{mL}$. Las cepas se sembraron en agar Sabouraud y se incubaron a $37^{\circ} \mathrm{C}$ durante $24 \mathrm{~h}$. Posteriormente se preparó un inóculo de cada cepa (Mc Farland de 0,5) y se realizó una dilución 1:1000; luego se sembraron $100 \mu \mathrm{L}$ de esta dilución en las placas de microdilución. Las placas se incubaron a $37^{\circ} \mathrm{C}$ durante $24 \mathrm{~h}$, en ausencia de luz. Finalmente, se realizó una lectura visual de las CIMs considerando el $50 \%$ de inhibición de crecimiento. Adicionalmente se tomaron $3 \mu \mathrm{L}$ de muestra de los pocillos y se sembró en un agar Sabouraud para evaluar si la actividad inhibitoria es fungistática o fungicida.

\section{Actividad antifúngica de lisados de melanocitos}

Se hicieron crecer melanocitos humanos HEMa-LP $\left(\right.$ Invitrogen $\left.{ }^{\circledR}\right)$ en Medio $254\left(\right.$ Gibco $\left.^{\circledR}\right)$ alcanzando un total de $10^{6}$ células. Luego, las células fueron estimuladas con $50 \mu \mathrm{g} / \mathrm{mL}$ de proteínas de extractos de C. albicans (blastoconidia e hifas) por 72 horas, y posteriormente los melanocitos fueron centrifugados a $800 \mathrm{rpm}$ por $10 \mathrm{~min}$. Los pellets fueron resuspendidos en $1 \mathrm{~mL}$ de PBS para luego ser lisados a $95^{\circ} \mathrm{C}$ durante $30 \mathrm{~min}$. Adicionalmente se preparó una suspensión de C. albicans ATCC SC5314 a una escala de Mc Farland de 0,5 y se realizó una dilución de 1:1.000; se tomaron $10 \mu \mathrm{L}$ del inóculo diluido y se agregaron a $500 \mu \mathrm{L}$ de extracto lisado de melanocitos. Posteriormente se hizo una siembra en rastrillo de 50 $\mu \mathrm{L}$ de las soluciones de trabajo en agar Sabouraud en triplicado a las 0,$5 ; 2$ y $24 \mathrm{~h}$ de incubación a $37^{\circ} \mathrm{C}$. Finalmente, se realizó recuento de ufc (unidad formadora de colonias). El mismo experimento fue realizado con células de melanoma de ratón B16 aportadas por Mercedes López del Programa de Inmunología, ICBM, Facultad de Medicina, Universidad de Chile y queratinocitos humanos HEKa(Invitrogen $\left.{ }^{\circledR}\right)$ como control.

\section{Análisis estadístico}

El análisis estadístico se hizo usando comparación de medias mediante t-Student de dos colas y ANOVA, utilizando el programa GraphPad 5.0.

\section{Resultados}

En el ensayo de susceptibilidad se observó un efecto inhibitorio de melanina sintética en la totalidad de las cepas analizadas (Figura 1), lo cual se verificó en la siembra en agar Sabouraud (Figura 2). Los rangos de CIM fueron $0,09-50 \mu \mathrm{g} / \mathrm{mL}$ y la CIM a la cual se inhibió $50 \%$ del total de cepas analizadas $\left(\mathrm{CIM}_{50}\right)$ fue de $6,25 \mu \mathrm{g} / \mathrm{mL}$. Además, se observó que melanina tuvo actividad antifúngica en cepas susceptibles, susceptibles dosis-dependiente y

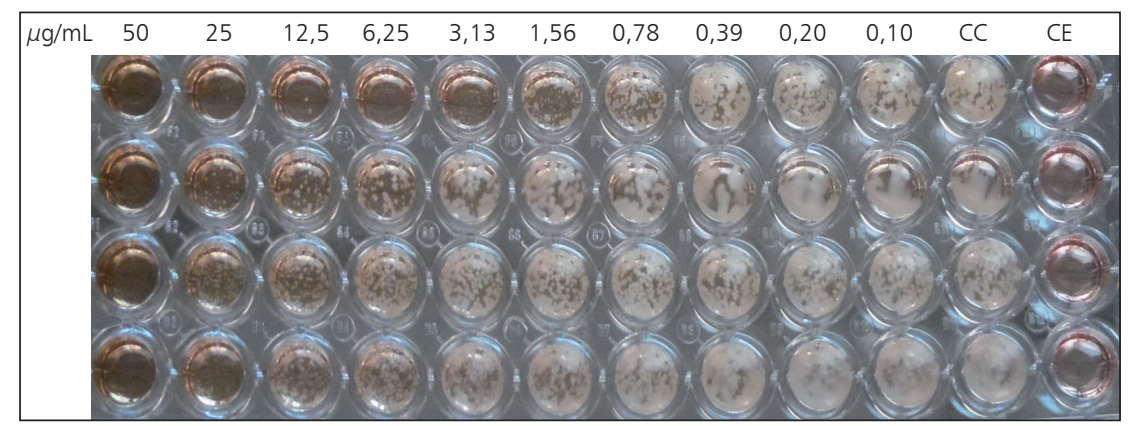

Figura 1. Efecto inhibitorio de melanina sintética sobre el crecimiento de cepas de Candida spp. CC: control de crecimiento, CE: control de esterilidad.

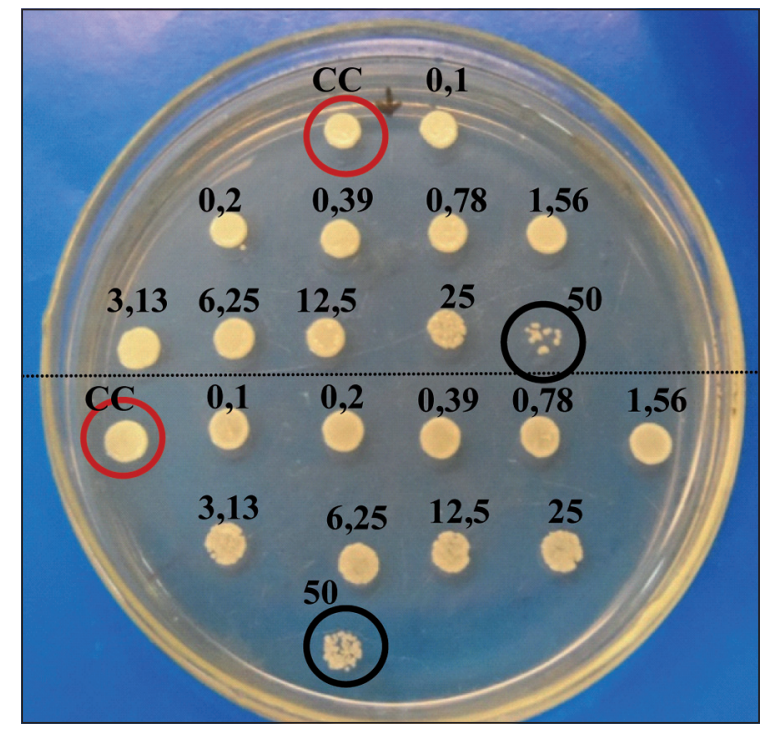

Figura 2. Verificación en agar Sabouraud del efecto inhibitorio de melanina sintética sobre el crecimiento de dos cepas de Candida spp. Los círculos indican el CC (Control de crecimiento) y siembra del pocillo con concentración de melanina de $50 \mu \mathrm{g} / \mathrm{mL}$. 
Tabla 1. Concentraciones inhibitorias mínimas (CIMs) a melanina y fluconazol en cepas de Candida albicans provenientes de aislados clínicos

\begin{tabular}{|ccc|} 
Especie $\quad$ Melanina & Fluconazol & $\begin{array}{c}\text { Categoría } \\
\text { susceptibilidad* }\end{array}$ \\
\hline
\end{tabular}

$\begin{array}{llll}\text { C. albicans } & 0,125 & 0,03 & \text { S } \\ \text { C. albicans } & 6,25 & 0,125 & \text { S } \\ \text { C. albicans } & 6,25 & 0,125 & \text { S } \\ \text { C. albicans } & 25 & 0,125 & \text { S }\end{array}$

$\begin{array}{llll}\text { C. albicans } & 25 & 0,125 & \text { S } \\ \text { C. albicans } & 25 & 0,125 & \text { S } \\ \text { C alcans } & 25 & 0,125 & \text { S }\end{array}$

$\begin{array}{llll}\text { C. albicans } & 0,19 & 0,25 \\ \text { C. albicans } & 3,125 & 0,25\end{array}$

$\begin{array}{lll}\text { C. albicans } & 3,125 & 0,25\end{array}$

$\begin{array}{lll}\text { C. albicans } & 6,25 & 0,25 \\ \text { C. albicans } & 6,25 & 0,25\end{array}$

$\begin{array}{lll}\text { C. albicans } & 12,5 & 0,25\end{array}$

$\begin{array}{lll}\text { C. albicans } \quad 12,5 & 0,25\end{array}$

$\begin{array}{lll}\text { C. albicans } & 12,5 & 0,25 \\ \text { C. albicans } & 12,5 & 0,25\end{array}$

$\begin{array}{lll}\text { C. albicans } \quad 12,5 & 0,25\end{array}$

$\begin{array}{lll}\text { C. albicans } & 12,5 & 0,25\end{array}$

$\begin{array}{lll}\text { C. albicans } & 12,5 & 0,25 \\ \text { C. albicans } & 25 & 0,25\end{array}$

$\begin{array}{llll}\text { C. albicans } & 25 & 0,25 & \text { S }\end{array}$

$\begin{array}{lll}\text { C. albicans } & 50 & 0,25 \\ \text { C. albicans } & 50 & 0,25\end{array}$

$\begin{array}{lll}\text { C. albicans } & 0,09 & 0,5 \\ \text { C. albicans } & 0,09 & 0,5\end{array}$

$\begin{array}{llll}\text { C. albicans } & 0,09 & 0,5 & \text { S } \\ \text { C. albicans } & 0,78 & 8 & \text { S } \\ \text { C. albicans } & 1,56 & 8 & \text { S } \\ \text { C. albicans } & 0,78 & 16 & \text { SDD } \\ \text { C. albicans } & 1,56 & 16 & \text { SDD } \\ \text { C. albicans } & 1,56 & 16 & \text { SDD } \\ \text { C. albicans } & 6,25 & 16 & \text { SDD } \\ \text { C. albicans } & 6,25 & 64 & \mathrm{R} \\ \text { C. albicans } & 6,25 & 64 & \mathrm{R} \\ \text { C. albicans } & 12,5 & 64 & \mathrm{R}\end{array}$

*Susceptibilidad a fluconazol S: Susceptible, SDD: Susceptible DosisDependiente, R: Resistente.

resistentes a fluconazol, tanto en las cepas de C. albicans (Tabla 1) como en cepas no-albicans (Tabla 2).

Al analizar la distribución de las CIMs, tanto en cepas clínicas como en cepas ATCC, de acuerdo a la especie se
Tabla 2. Concentraciones inhibitorias mínimas (CIMs)

a melanina y fluconazol en cepas de Candida no-albicans provenientes de aislados clínicos.

\begin{tabular}{|c|c|c|c|}
\hline Especie & Melanina & Fluconazol & $\begin{array}{c}\text { Categoría } \\
\text { susceptibilidad* }\end{array}$ \\
\hline C. famata & 25 & 0,25 & S \\
\hline C. famata & 12,5 & 8 & S \\
\hline C. famata & 6,25 & 16 & SDD \\
\hline C. glabrata & 6,25 & 8 & $S$ \\
\hline C. glabrata & 6,25 & 8 & S \\
\hline C. glabrata & 12,5 & 8 & s \\
\hline C. glabrata & 6,25 & 8 & S \\
\hline C. glabrata & 6,25 & 2 & S \\
\hline C. glabrata & 3,12 & 32 & SDD \\
\hline C. glabrata & 3,12 & 16 & SDD \\
\hline C. glabrata & 3,12 & 16 & SDD \\
\hline C. glabrata & 0,09 & 16 & SDD \\
\hline C. glabrata & 6,25 & 16 & SDD \\
\hline C. glabrata & 0,125 & 16 & SDD \\
\hline C. glabrata & 6,25 & 16 & SDD \\
\hline C. krusei & 25 & 0,25 & S \\
\hline C. krusei & 25 & 0,25 & S \\
\hline C. krusei & 50 & 64 & $\mathrm{R}$ \\
\hline C. parapsilosis & 6,25 & 2 & S \\
\hline C. parapsilosis & 25 & 0,25 & S \\
\hline C. parapsilosis & 1,56 & 0,25 & S \\
\hline C. tropicalis & 6,25 & 16 & SDD \\
\hline C. tropicalis & 3,125 & 16 & SDD \\
\hline
\end{tabular}

encontró que $C$. glabrata presentó CIMs más bajas en promedio que $C$. albicans $(\mathrm{p}<0,0001)$, mientras que $C$. krusei presentó CIMs más altas a melanina $(\mathrm{p}=0,0085)$ (Figura 3).

En los experimentos de inhibición de C. albicans, utilizando lisados de melanocitos estimulados con blastoconidias e hifas, se observó una inhibición del crecimiento de C. albicans, expresado en ufc, a las 2 horas de exposición, en comparación a las 0,5 horas, cuya diferencia fue estadísticamente significativa (Figura 4). Aun cuando C. albicans mostró un mayor crecimiento a las 24 horas de exposición en relación a las 0,5 y $2 \mathrm{~h}$, se observó una disminución significativa del crecimiento de la levadura al estar expuesta a lisados de melanocitos estimulados con hifas, en comparación a lisados no estimulados y estimulados con blastoconidias. 


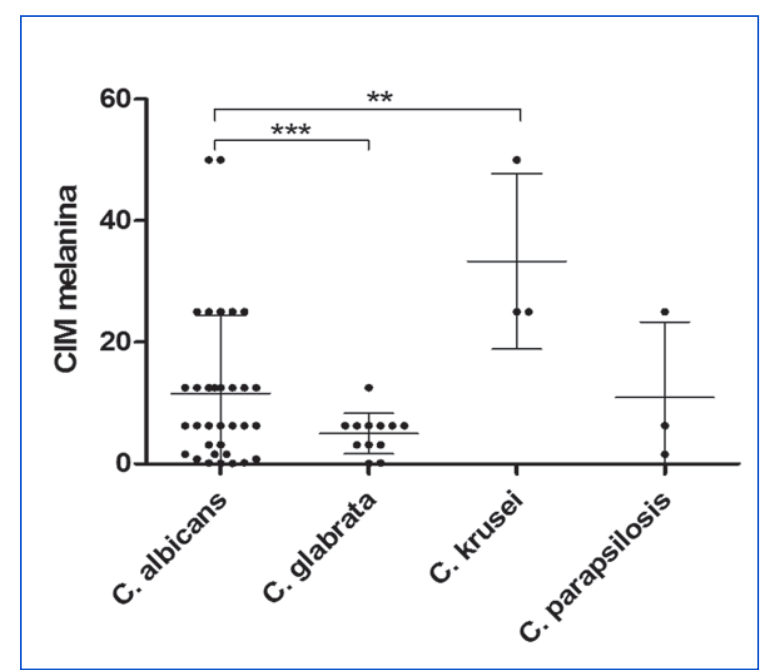

Figura 3. Representación gráfica de CIMs a melanina de cepas clínicas de C. albicans, C. glabrata, C. krusei y C. parapsilosis. $* * * p<0,0001 ; * * p<0,01$. CIM expresada en $u g / m l$.

Al comparar recuentos de colonias de C. albicans expuesta a lisados de melanocitos y queratinocitos se observó que, aunque a las 0,5 horas de exposición a melanocitos hubo un mayor crecimiento de C. albicans, mientras que a las 2 y 24 horas, el recuento fue menor (Figura 5).

Finalmente, para evidenciar mejor las diferencias entre células con melanina y sin melanina, cepas de C. albicans fueron expuestas durante 24 horas a lisados de células de melanoma de ratón y queratinocitos. Adicionalmente, para estimar el contenido de melanina, se midió la densidad óptica (OD) a $492 \mathrm{~nm}$ de cada lisado. Se observó que a una mayor OD hay una disminución de las ufc recuperadas luego de exponer cepas de C. albicans a lisados. (Figura 6).

\section{Discusión}

Numerosos estudios han demostrado que la función de los melanocitos no sólo comprende la protección del daño por radiación UV, sino que además, actúan como células inmunes que reconocen estructuras conservadas presentes en los microorganismos, llamadas PAMPs (pathogenassociated molecular patterns); es así como en algunos estudios se ha descrito que la melanina, sintetizada en los melanocitos, presenta actividad antimicrobiana y que los melanocitos al ser expuestos a PAMPs incrementan la síntesis de melanina, por lo que el proceso de melanización podría ser importante como mecanismo protector de la respuesta inmune innata ${ }^{15}$.

Aunque la melanina es producida por hongos patógenos y se considera un factor de virulencia ${ }^{16,17}$, también presenta actividad antimicrobiana ${ }^{1,8}$. Existen diversos

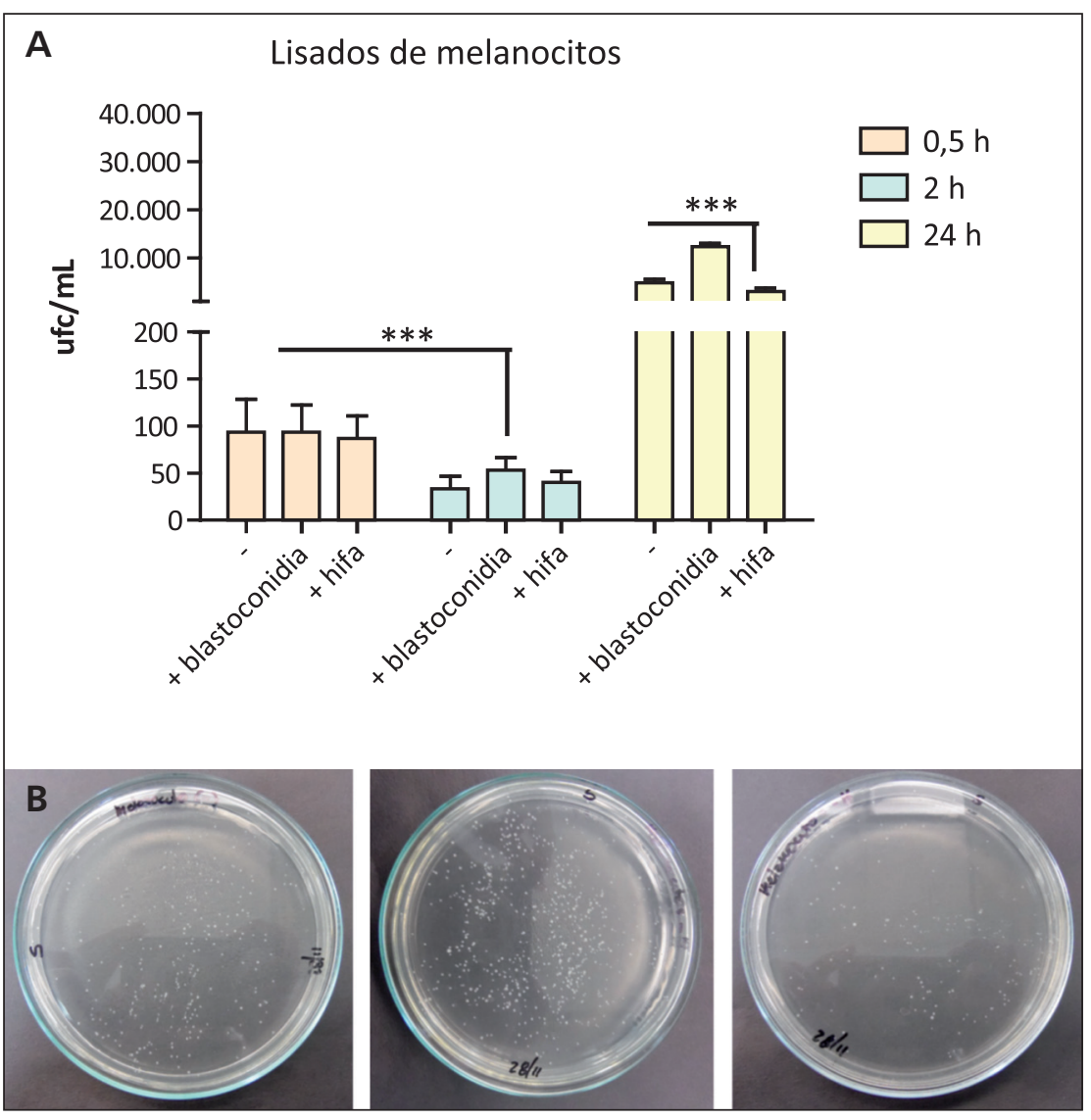

Figura 4. Recuento de colonias de C. albicans expuesta a lisados de melanocitos no estimulados, estimulados con extracto de blastoconidia y con extracto de hifa. A) Recuentos a las 0,5, 2 y 24 horas. B) Fotografía de recuentos en placa de UFC a las $24 \mathrm{~h}$ de incubación. *** $p<0,0001$.

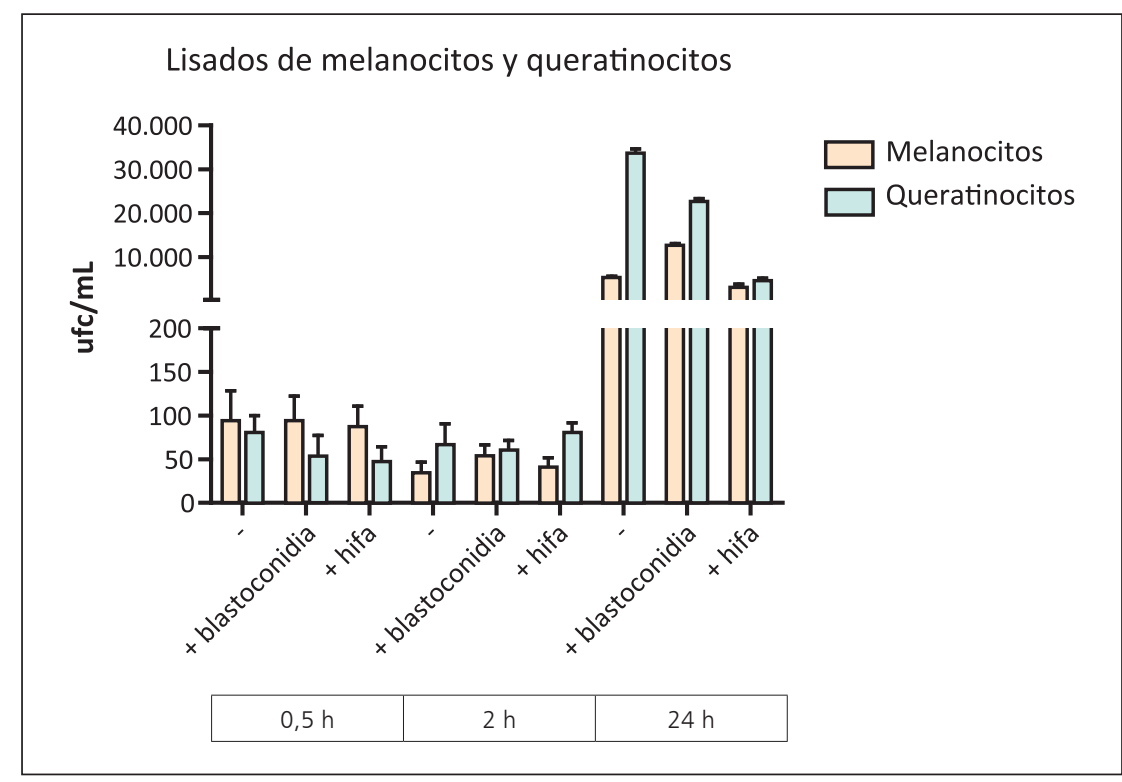

Figura 5. Recuento de colonias de C. albicans expuestas a lisados de melanocitos y queratinocitos, a las 0,$5 ; 2$ y 24 h de exposición. 
Figura 6. Relación entre el OD492 y el recuento de colonias de C. albicans expuesta a lisados de queratinocitos y células de melanoma de ratón B16 A) OD de lisados celulares. B) Recuento de colonias de C. albicans expuesta a lisados celulares. ${ }^{*} \mathrm{p}<0,05$; ns: no significativo.

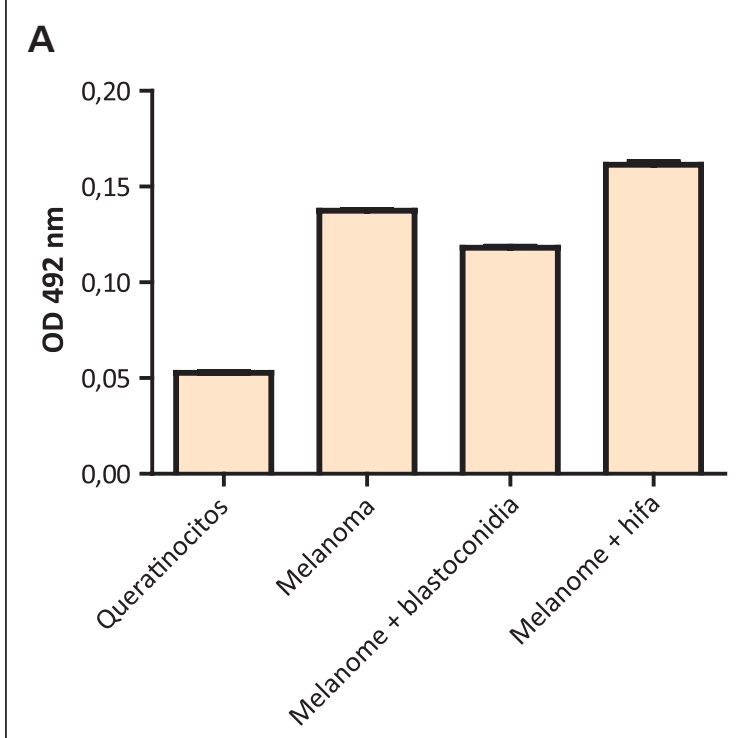

B

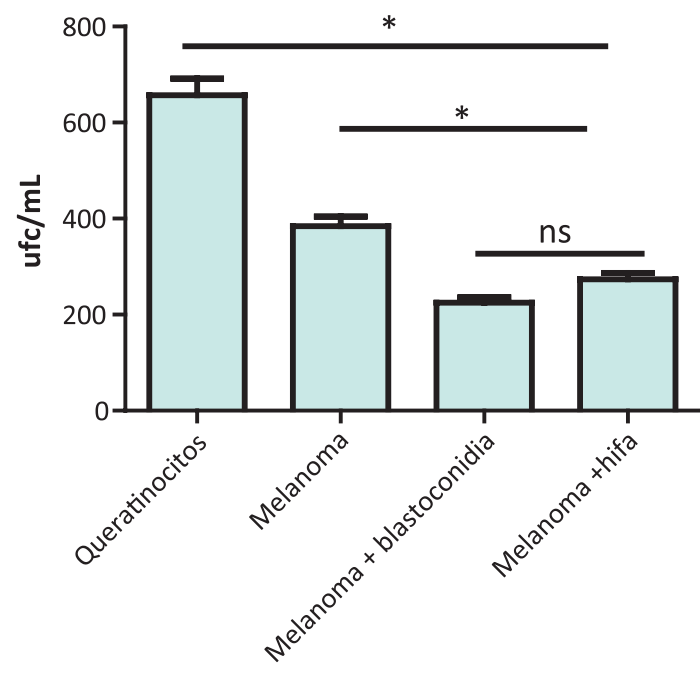

tipos de melanina, las cuales además difieren estructuralmente entre las especies fúngicas ${ }^{17}$, pudiendo otorgarle diversas propiedades.

En el presente trabajo se evaluó la actividad antifúngica de la melanina frente a cepas clínicas y ATCC de Candida spp., demostrando que la melanina presenta actividad antifúngica a concentraciones iguales o inferiores a $50 \mu \mathrm{g} / \mathrm{mL}$.

Además, la melanina fue capaz de inhibir el crecimiento de cepas de Candida albicans y no-albicans sensibles dosis dependiente (SDD) y resistentes a fluconazol, antifúngico más utilizado a nivel clínico en nuestro país ${ }^{18}$. Cabe destacar que $C$. glabrata, especie que tiende a presentar mayor resistencia a los antifúngicos convencionales, fue la especie más sensible a melanina, lo que sugiere un mecanismo defensivo importante de piel y mucosa, además de una probable alternativa de tratamiento interesante de estudiar.

Los lisados de melanocitos mostraron un efecto inhibitorio sobre el crecimiento de $C$. albicans a las 2 horas de exposición. Por otra parte, a las 24 h se observó que melanocitos estimulados con hifas inhiben mucho más el crecimiento de $C$. albicans que melanocitos estimulados con blastoconidias. Esto es interesante pues probablemente el estado patogénico de C. albicans (hifa), induce una mayor melanización, lo cual sugiere que melanocitos podrían discriminar entre blastoconidia e hifa, al igual que otras células inmunes no profesionales como células epiteliales $^{19,20}$.

Adicionalmente, se observó que células con un alto contenido de melanina, como las células de melanoma de ratón $\mathrm{B} 16$, inducen una mayor inhibición del crecimiento de C. albicans, principalmente si éstas fueron estimuladas con extractos de la levadura.

El mecanismo de acción de la melanina no se conoce aún; sin embargo, se ha descrito actividad inhibitoria y fungicida de intermediarios de quinonas reactivas producidas durante la biosíntesis de melanina per se y/o por la producción de peróxido de hidrógeno debido a la estructura aromática de estos componentes ${ }^{1}$. También hay evidencia que sugiere que la melanina es capaz de absorber varios compuestos orgánicos e inorgánicos actuando como un "cationito"; mediante esta propiedad, la melanina es capaz de unir toxinas bacterianas como la toxina botulínica $^{8}$ y podría absorber diferentes compuestos de la pared celular de $C$. albicans o directamente romper la membrana plasmática. Se requieren más estudios para comprender cabalmente el mecanismo de acción de melanina.

En base a los resultados anteriormente expuestos, es posible concluir que la melanina presenta una actividad antifúngica in vitro, capaz de inhibir cepas susceptibles, dosis-dependiente y resistentes a fluconazol, siendo $C$. glabrata la especie más sensible a melanina en este estudio. El efecto inhibitorio parece ser fungistático principalmente frente a la exposición con lisados de células melanizadas.

Agradecimientos. Agradecemos al Curso Unidades de Investigación, de la Facultad de Medicina Universidad de Chile versión 2012 por aportar recursos para realizar este trabajo y a Anna Di Nardo, de la Universidad de California San Diego (UCSD), San Diego, USA por apoyar el inicio de esta línea de investigación. 


\section{Resumen}

Introducción: Los melanocitos son células presentes en piel y en mucosas que sintetizan melanina, además de citoquinas. Es sabido que melanina presenta actividad antimicrobiana y que los melanocitos se melanizan al ser expuestos a moléculas microbianas. Objetivo: Estudiar la actividad antifúngica de melanina en cepas clínicas de Candida spp. Metodología: Se midió la concentración inhibitoria mínima (CIM) a melanina, de 4 cepas de Candida ATCC (C. albicans SC5314, C. parapsilosis 22019, C. glabrata 2001 y C. krusei 6258) y 56 aislados clínicos de Candida spp. (33 $C$. albicans, 12 C. glabrata, 3 C. famata, 3 C. krusei, 3 C. parapsilosis, 2 C. tropicalis) mediante un método de microdilución en caldo. Además se estudió el efecto antifúngico de lisados de melanocitos y células de melanoma de ratón en C. albicans. Resultados: Melanina inhibió las cepas analizadas, incluso cepas susceptibles dosis-dependiente y resistentes a fluconazol, siendo los rangos de CIM y CIM $_{50}$ de $0,09-50 \mu \mathrm{g} / \mathrm{mL}$ y $6,25 \mu \mathrm{g} /$ $\mathrm{mL}$, respectivamente. Los lisados de células pigmentadas inhibieron C. albicans. Conclusiones: Melanina es capaz de inhibir cepas clínicas de Candida spp. La melanización podría ser un importante mecanismo protector de los melanocitos.

\section{Referencias bibliográficas}

1.- Plonka P M, Passeron T, Brenner M, Tobin D J, Shibahara S, Thomas A, et al. What are melanocytes really doing all day long...? Exp Dermatol 2009; 18 (9): 799-819.

2.- Sulaimon S S, Kitchell B E. The biology of melanocytes. Vet Dermatol. [Review] 2003; 14 (2): $57-65$

3.- Jacobson E S. Pathogenic roles for fungal melanins. Clin Microbiol Rev 2000; 13 (4): 708-17.

4.- Butler M J, Gardiner R B, Day A W. Fungal melanin detection by the use of copper sulfidesilver. Mycologia 2005; 97 (2): 312-9.

5.- Slominski A, Tobin D J, Shibahara S, Wortsman J. Melanin pigmentation in mammalian skin and its hormonal regulation. Physiol Rev 2004; 84 (4): 1155-228.

6.- Lin J Y, Fisher D E. Melanocyte biology and skin pigmentation. Nature. [Research Support, N.I.H., Extramural Research Support, Non-U.S. Gov't Review] 2007; 445 (7130): 843-50.

7.- Riley P A. Melanin. Int J Biochem Cell Biol 1997; 29 (11): 1235-9.

8.- Mackintosh J A. The antimicrobial properties of melanocytes, melanosomes and melanin and the evolution of black skin. J Theor Biol 2001; 211 (2): 101-13.

9.- $\quad$ Kang H Y, Park T J, Jin S H. Imiquimod, a Toll-like receptor 7 agonist, inhibits melanogenesis and proliferation of human melanocytes. J Invest Dermatol 2009; 129 (1): 243-6.

10.- Hill H Z. The function of melanin or six blind people examine an elephant. Bioessays 1992; 14 (1): 49-56.

11.- Niggli H J. Comparative studies on the correlation between pyrimidine dimer formation and tyrosinase activity in cloudman S91 melanoma cells after ultraviolet-irradiation. Photochem Photobiol 1990; 52 (3): 519-24.

12.- Jin S H, Kang H Y. Activation of Tolllike receptors $1,2,4,5$, and 7 on human melanocytes modulate pigmentation. Ann Dermatol 2010; 22 (4): 486-9.

13.- Lim C S, Rosli R, Seow H F, Chong P P. Candida and invasive candidiasis: back to basics. Eur J Clin Microbiol Infect Dis 2012; 31 (Pt 3): 21-31.

14.- Rebera A, Guarrera M. Racial difference in experimental skin infection with Candida albicans. Dermatol 1988; 68 (4): 165-8.

15.- Ahn J H, Park T J, Jin S H, Kang H Y. Human melanocytes express functional Toll-like receptor 4. Exp Dermatol 2008; 17 (5): 412-7.

16.- Taborda C P, da Silva M B, Nosanchuk J D, Travassos L R. Melanin as a virulence factor of Paracoccidioides brasiliensis and other dimorphic pathogenic fungi: a minireview. Mycopathologia 2008; 165 (4-5): 331-9.

17.- Wang Y, Aisen P, Casadevall A. Cryptococcus neoformans melanin and virulence: mechanism of action. Infect Immun 1995; 63 (8): 3131-6.

18.- Pappas P G, Kauffman C A, Andes D, Benjamin D K, Jr., Calandra T F, Edwards J E, Jr., et al. Clinical practice guidelines for the management of candidiasis: 2009 update by the Infectious Diseases Society of America. Clin Infect Dis 2009; 48 (5): 503-35.

19.- Netea M G, Kullberg B J. Epithelial sensing of fungal invasion. Cell Host Microbe. [Comment]. 2010; 8 (3): 219-20.

20.- Netea M G, van der Meer J W, Kullberg B J. Both TLR2 and TLR4 are involved in the recognition of Candida albicans. Reply to "TLR2, but not TLR4, triggers cytokine production by murine cells in response to Candida albicans yeasts and hyphae" by Gil and Gozalbo, Microbes and Infection 8 (2006) 2823-2824. Microbes Infect 2006; 8 (12-13): 2821-2; author reply 3-4. 